\title{
ONE Year LATER...
}

I

is exactly a year ago, November 1997, that I wrote my first editorial for this journal. It is therefore appropriate to review our achievements and define our shortcomings. I had hoped to make the journal more user friendly and less intimidating so that there would be an easy flow of information through submission of manuscripts, letters to the editor, notes, opinions and feelings. I had hoped to hear from a larger representation of physiotherapists in South Africa and abroad as well as our physiotherapy assistants who play such an important role in our profession.

You are the judges of how much has happened. I believe that we have made a valuable beginning although there is still much to be done and thank you to all those who have been involved and supported me. I read with interest Kathy Henderson's editorial in the March 1998 edition of the Australian Journal of Physiotherapy. In this Journal she introduces a new style of paper, "the short scientific report". She believes that this should assist to document the science and practice of physiotherapy in Australia. She also reiterates the importance of clinical notes and reviews.

I believe that it is important to spell out the policy of the editorial board of this journal again. We will encourage and assist in the publication of good Research Articles. We invite Literature Reviews, Case Studies as well as Clinical Notes and Clinical Reviews. We want to publish interesting information on treatments and techniques as well as thoughts, opinions and emotions. It is really a pity to exclude this kind of information because it doesn't meet up to the standards of what many believe to be true academic research. Do we really only want to publish research, which has followed strict scientific procedure? I think not! The editorial board will take the responsibility of ensuring that our journal will be of a standard that we can all be proud of and at the same time ensure that our readers feel free to submit manuscripts without being threatened.

In our leading article "Dimensions of Excellence" by Professor Ruth Grant, the rapid advances in every level of society all over the world and more especially in health care delivery and education is high-lighted. How to recognize this and prepare us for change is so aptly presented. She introduces us to the concept of the Sigmoid Curve Theory whereby a second curve introducing change needs to be initiated before the first curve dips downward. She states that those people who lead the second curve will not be the same people who led the first curve. Who are our leaders who are formulating policy and change? Surely they are the office-bearers of the S.A.S.P.

There must be many physiotherapists out there with new and original thinking! It is the function of this journal to reflect your views and the state of change in our profession. This information can only come from the readers of this journal if we are to succeed in providing you with a relevant journal. I will persist in seeking ways to instill a desire and motivation for people to publish, whether it be research or information or opinions.

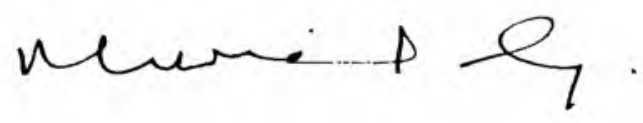

